\title{
Leading newspapers of Trinidad and Tobago
}

The Bomb w

The Clarion w, $d$

The Daily Mirror $\quad \mathrm{D}, d$

The East Indian Weekly w, $d$

The Express D

The Labour Leader w, $d$ Moko o

The Nation w

The People w, $d$

The PNM Weekly w, $d$

The Port of Spain Gazette

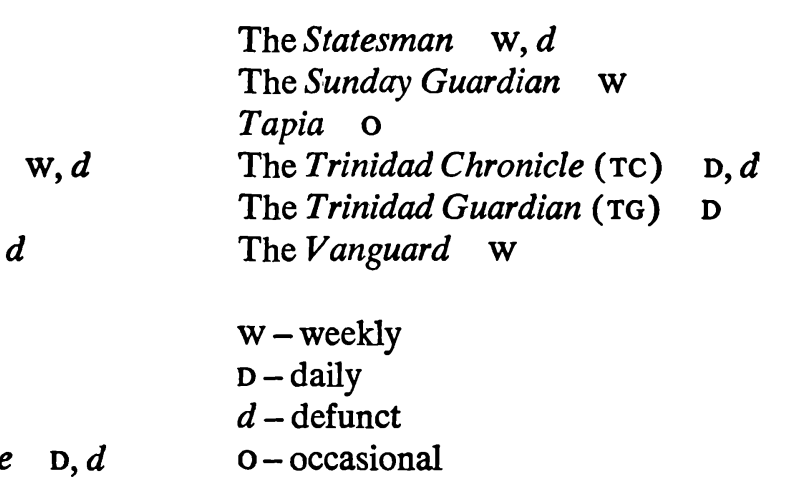

The Statesman w, $d$

The Sunday Guardian w

Tapia $\mathbf{0}$

The Trinidad Chronicle (TC) D, $d$

The Trinidad Guardian (TG) D

w - weekly

D-daily

o-occasional 
